\title{
Correlations between the incidence of childhood-onset Type I diabetes in Europe and HLA genotypes
}

\author{
K.S. Rønningen ${ }^{1}$, N. Keiding ${ }^{2}$, A. Green ${ }^{3}$ on behalf of Genomic Marker Contributors \\ and the EURODIAB ACE Study Group* \\ ${ }^{1}$ Department of Population Health Sciences, National Institute of Public Health, Oslo, Norway \\ ${ }^{2}$ Department of Epidemiology and Social Medicine, Århus University, Århus, Denmark \\ ${ }^{3}$ Department of Biostatistics, University of Copenhagen, Copenhagen, Denmark
}

\section{Abstract}

There are large variations in the incidence of Type I (insulin-dependent) diabetes mellitus within Europe, ranging from 3.2 cases per 100000 person-years in the Republic of Macedonia to more than 40 new cases per 100000 person-years in Finland. This variation could be caused by differences in the distribution of genetic susceptibility markers, by differences in the distribution of environmental disease determinants or by a combination of both. To assess how much genes contribute to this variation, we correlated the level of incidence of Type I diabetes with the prevalence in the general population of genetic susceptibility and protective markers encoded by the human leukocyte antigen (HLA)-DQ loci. Positive association was found for the combined group of genotypes associated with Type I diabetes risk $(p<0.001)$. The whole positive effect was, however, accounted for by the $H L A-D Q 2 /$ DQ8 (DQA1*0501-DQB1*0201/DQA1*0301-DQ-
$\mathrm{B} 1 * 0302)$ and $H L A-D Q 4 / D Q 8$ (DQA1*0401DQB1*0402/DQA1*0301-DQB1*0302) genotypes $(p<0.001$ and $p<0.004$, respectively). No correlation was found between incidence of Type I diabetes and population prevalence of genotypes not encoding for aspartate on position 57 on the HLA-DQ $\beta$ chain. It was not possible to detect any negative correlation between Type I diabetes incidence and the prevalence of $H L A$-genotypes conferring protection against Type I diabetes in a population (HLADQA1*0102-DQB1*0602/X). The results suggest that a substantial part of the transnational variation in the incidence of childhood-onset Type I diabetes in Europe is explained by variations between populations in the distribution of particular DQ genotypes which confer a high risk of Type I diabetes in the general population. [Diabetologia (2001) 44 [Suppl 3]: B 51-B 59]

Keywords $D Q$ genotypes, Europe, incidence, populations, Type I diabetes.
Recent research has identified two major features which influence the frequency and distribution Type I (insulin-dependent) diabetes mellitus in childhood. First, in the northern European countries a steady increase, about $3 \%$ annually in incidence (and hence,

Corresponding author: K. S. Rønningen, Department of Population Health Sciences, National Institute of Public Health, P. O. BOX 4404 Nydalen, N-0403 Oslo, Norway

Abbreviations: HLA, Human leukocyte antigen, Asp57, aspartic acid at $\mathrm{DQ} \beta$-chain residue 57 , Non-Asp57, amino acids other than aspartic acid at $\mathrm{DQ} \beta$-chain residue 57 .

* see Acknowledgments disease risk), has been observed, during the last decades [1]. Second, on the global scale Europe has the highest risk of Type I diabetes that has been measured, ranging tenfold from Finland (highest) to South-eastern Europe (lowest) but with striking regional variations $[1-3]$.

Type I diabetes is caused by the interaction of genetic factors and environmental factors. The rise in Type I diabetes incidence cannot be solely explained by genetic mechanisms but it is still not known whether the geographical variation in diabetes incidence is attributable to differences in the distributions of environmental factors or genes, or a combination of both. Correlating the degree of population risk of Type I di- 
Table 1. Incidence data used for analysis, by population

\begin{tabular}{|c|c|c|c|c|}
\hline Country & Abbreviation & $\begin{array}{l}\text { Number of } \\
\text { incident cases }\end{array}$ & $\begin{array}{l}\text { Estimated number of } \\
\text { person-years at risk }\end{array}$ & $\begin{array}{l}\text { Standardized } \\
\text { incidence rats }{ }^{\text {a }} \\
(0-14 \text { years }) \text { per } 100000\end{array}$ \\
\hline Finland & FIN & 1014 & 2872521 & 35.30 \\
\hline Sweden & $\mathrm{S}$ & 3836 & 15721311 & 24.40 \\
\hline Denmark & DK & 226 & 1381418 & 16.36 \\
\hline Norway & $\mathrm{N}$ & 491 & 2316038 & 21.20 \\
\hline The Netherlands & NL & 422 & 3236196 & 13.04 \\
\hline Czech Republic & $\mathrm{CZ}$ & 1113 & 12926829 & 8.61 \\
\hline Austria & A & 754 & 8249453 & 9.14 \\
\hline Germany & $\mathrm{D}$ & 1201 & 10544337 & 11.39 \\
\hline Spain & $\mathrm{E}$ & 847 & 6847211 & 12.37 \\
\hline Belgium & $\mathrm{B}$ & 112 & 966350 & 11.59 \\
\hline Israel & ISR & 433 & 7389078 & 5.86 \\
\hline Poland & POL & 1182 & 19003215 & 6.22 \\
\hline Hungary & HUN & 821 & 9287330 & 8.84 \\
\hline Republic of Macedonia & MAC & 93 & 2952381 & 3.15 \\
\hline Romania & ROM & 138 & 2782258 & 4.96 \\
\hline Bulgaria & BUL & 513 & 6349010 & 8.08 \\
\hline \multirow[t]{2}{*}{ Russia } & RUS & 351 & 5441860 & 6.45 \\
\hline & & 18417 & 159079987 & 11.58 \\
\hline
\end{tabular}

a Standardized incidence rate is based on groups matched for (0-4, 5-9 and 10-14 years) of equal size

abetes with the prevalence of genetic susceptibility markers in the general population might throw light on this issue.

About 20 genomic regions have been identified which could contribute to Type I diabetes development [4-6]. The HLA region on the short arm of chromosome 6 is the most important, accounting for $42 \%$ of the familiar clustering of Type I diabetes [4]. Type I diabetes is most strongly associated with $H L A-D Q A 1$ and $D Q B 1$ genes [7-10]. Several models have been put forward to explain this association. One study suggested that alleles encoding amino acids other than aspartic acid at $D Q \beta$ chain residue 57 (non-Asp57) are associated with Type I diabetes susceptibility [7]. Alleles encoding Asp57 appear to be associated with dominant protection [11]. However, other later studies indicate that the Type I diabetes association is more complex $[12,13]$. Investigators have proposed that Type I diabetes is primarily associated with $\mathrm{DQ} \alpha \beta$ heterodimers composed of a $\mathrm{DQ} \alpha$ chain having arginine at residue 52 in combination with a non-Asp57 DQ $\beta$-chain $[14,15]$. We have suggested that Type I diabetes could be primarily associated with five or six particular cis-encoded or transencoded DQ $\alpha \beta$ heterodimers [16,17]. The $\mathrm{DQ} \alpha \beta$ heterodimer encoded by DQA $1 * 0102$ and DQB $1 * 0602$ (found on a $D R 2$ haplotype) seems to confer dominant protection $[9,17,18]$. Data from the 11th International Histocompatibility Workshop where 981 unre- lated Type I diabetes patients and 2228 healthy control subjects were genomically $H L A$ class II typed, revealed that the highest Type I diabetes risk among Caucasians is associated with six $D Q$ genotypes [19]. Our ecological analysis tests associations between the $H L A-D Q$ genotypes in a population with incidence rates of Type I diabetes.

\section{Materials and methods}

Type I diabetes incidence. New data on the incidence of Type I diabetes in childhood has been obtained from the EURODIAB studies [1, 2]. Our analysis uses data from the period 1989-1994 [1]. To increase statistical power, the incidence estimates from Finland and Sweden have been based on data covering their respective total populations [3]. The same sources also provided information on incidence in Russia. The incidence data which has formed the basis of our analyses is shown in Table 1.

Genotype data. The $H L A-D Q A 1$ and $-D Q B 1$ genotypes were available for 11736 healthy control subjects (genomic marker contributors) for 25 of the countries participating in the EURODIAB ACE network. The HLA class II genotyping was done at the local laboratories of the various network centres and was mainly carried out by polymerase chain reaction with subsequent hybridisation to sequence-specific oligonucleotide probes (PCR-SSOP) according to the protocols of the $11^{\text {th }}$ International HLA Workshop, while some centres used polymerase chain reactions with sequence-specific primers [20,21]. 


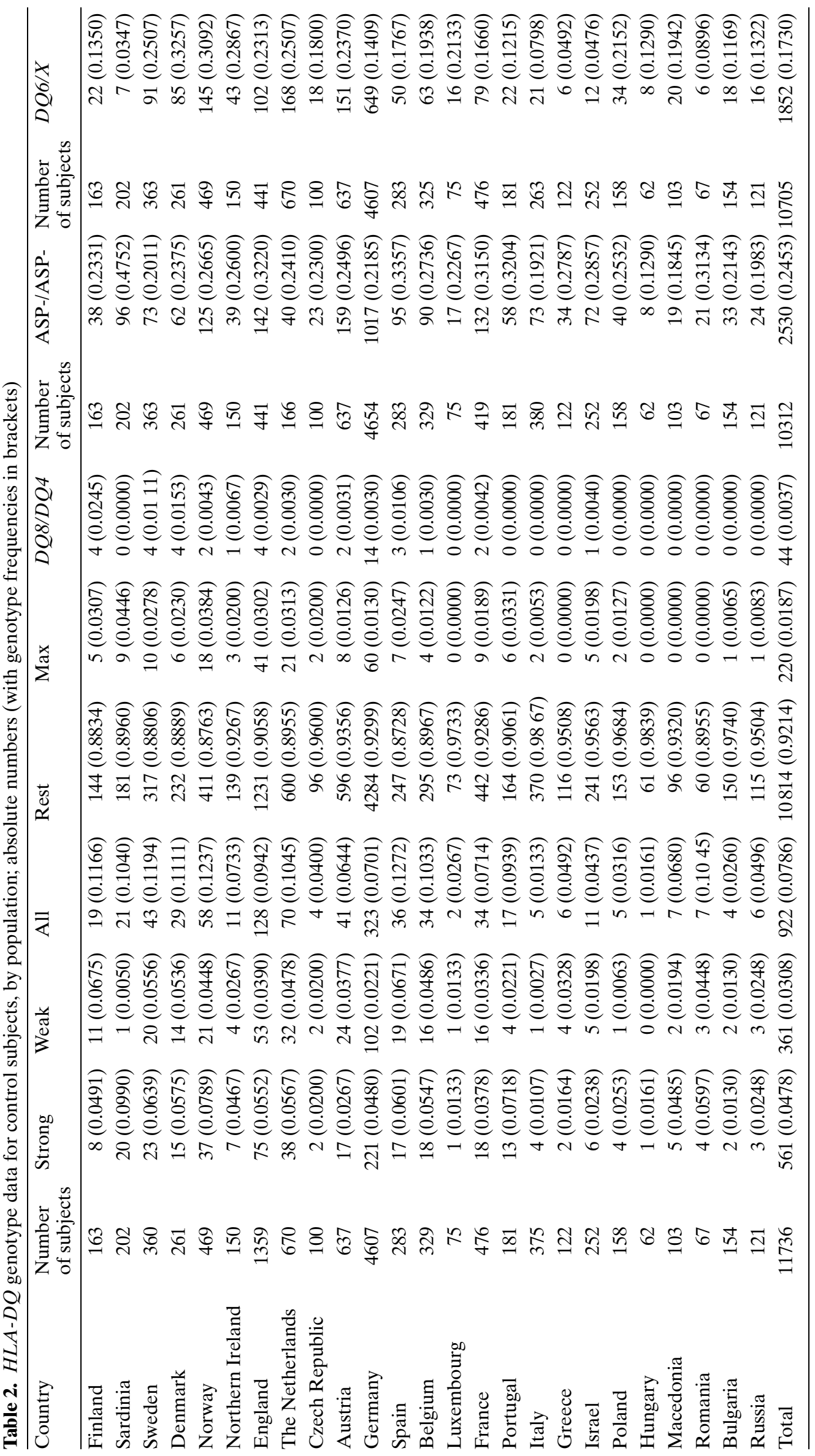


Table 3. Summary of correlation analysis: HLA-DQ genotype frequency compared with population incidence of Type I diabetes

\begin{tabular}{|c|c|c|c|}
\hline \multirow[b]{2}{*}{ HLA-DQ genotype class } & \multirow[b]{2}{*}{ HLA-DQ genotypes involved } & \multicolumn{2}{|l|}{ Test of correlation } \\
\hline & & $\begin{array}{l}\text { Correlation } \\
\text { coefficient } \tau \text { (SEM) }\end{array}$ & $p$ \\
\hline All (Strong + Weak) & $D Q 2 / D Q 8 ; D Q 2 / D Q 2 ; D Q 8 / D Q 8 ; D Q 4 / D Q 8 ; D Q 5 / D Q 8 ; D Q 6 / D Q 8$ & $0.437(0.097)$ & $<0.001$ \\
\hline Strong & $D Q 2 / D Q 2 ; D Q 2 / D Q 8 ; D Q 8 / D Q 8$ & $0.413(0.123)$ & $<0.001$ \\
\hline $\operatorname{Max}$ & $D Q 2 / D Q 8$ & $0.540(0.099)$ & $<0.001$ \\
\hline Strong except Max & $D Q 2 / D Q 2 ; D Q 8 / D Q 8$ & $0.307(0.163)$ & 0.060 \\
\hline Weak & $D Q 4 / D Q 8 ; D Q 5 / D Q 8 ; D Q 6 / D Q 8$ & $0.337(0.136$ & 0.013 \\
\hline DQ4/DQ8 & $D Q 4 / D Q 8$ & $0.400(0.139)$ & 0.0040 \\
\hline Weak except DQ4/DQ8 & $D Q 5 / D Q 8 ; D Q 6 / D Q 8$ & $0.241(0.134)$ & 0.072 \\
\hline Rest & All genotypes not included in "All” & $-0.437(0.097)$ & $<0.001$ \\
\hline ASP- & All genotypes without haplotypes coding for Asp at pos. 57 of the $\mathrm{DQ} \beta$-chain & $0.200(0.156)$ & 0.20 \\
\hline DQ6/X & All genotypes that include DQB $1 * 0602$ & $0.287(0.156)$ & 0.066 \\
\hline
\end{tabular}

The $D Q$ genotypes were given a susceptibility score according to the formation of possible heterodimers, as suggested previously $[9,16]$. We combined the six genotypes associated with Type I diabetes risk in Caucasians into one increased risk category classified as the genotype "All" in the calculations $[19,22]$. Further separate analyses were performed for the category "Max" comprising the DQA1*0501DQB1*0201/DQA1*0301-DQB1*0302 (DQ2/DQ8) genotype, as well as for the category "Strong" comprising the "Max" (DQA1*0501-DQB1*0201/DQA1*0301-DQB1*0302) genotype together with the two homozygous combinations of its haplotypic components, DQA $1 * 0301-\mathrm{DQB} 1 * 0302 /$ DQA1*0301-DQB1*0302 (DQ8/DQ8) and DQA1*0501DQB1*0201 / DQA1*0501-DQB1*0201 (DQ2/DQ2). The remaining genotypes in the "All" class are denoted "Weak", and include DQA1*0101-DQB1*0501/DQA1*0301DQB1*0302 (DQ5/DQ8), DQA $1 * 0102-\mathrm{DQB} 1 * 0604 /$ DQA1*0301-DQB1*0302 (DQ6/DQ8) and DQA1*0401DQB1*0402/DQA1*0301-DQB1*0302 (DQ4/DQ8). In addition, we analysed the distribution of DQB1 non-Asp57 homozygosity (named genotype "ASP-") and of the Type I diabetes protective haplotype DQA1*0102-DQB1*0602 (named genotype " $D Q 6 / X$ ").

The genotype data, for each country is shown in Table 2. Even though genetic marker data exists from Ireland, this nation has not been included in the analysis because of the scarcity of epidemiological information, leaving Northern Ireland to represent the whole island.

Statistical analysis. An initial analysis was done by calculating Kendall's $\tau$ (with adjustment for ties) [23] to examine the correlation between genotype frequencies and Type I diabetes incidence rates. This analysis weights each country equally and does not allow the relationship between genotype frequency and Type I diabetes incidence rate to be quantified. A straightforward regression of incidence rate on genotype frequency would not be correct because of the uncertainty in both variables $[24,25]$. In our case the genotype frequencies and the Type I diabetes incidence rates are based on independent groups of individuals. This allowed us to develop a simple probability-based approach assuming binomial distribution of the $H L A-D Q$ genotypes and standard Poisson distribution of the incident cases. This yields directly the joint probability function

$L \propto \prod_{i=1}^{25} p_{i}^{X_{i}}\left(1-p_{i}\right)^{n_{i}-X_{i}} \lambda_{i}{ }^{D_{i}} e^{-\lambda_{i} S_{i}}$

with, for population $i$,

$X_{i}=$ number of individuals with high risk genotypes $n_{i}=$ total number of individuals genotyped

$p_{i}=$ population frequency of high risk genotype

$D_{i}=$ number of new Type I diabetes patients observed

$S_{i}=$ number of person-years observed

$\lambda_{\mathrm{i}}=$ population Type I diabetes incidence.

We hypothesised that if a linear association exists between Type I diabetes incidence and genotype frequency, which could be reduced to proportionality with no association and no incidence variation as the extreme. This hypothesis was formally tested by the probability ratio criterion, with the full model (free variation, hypothesis $\mathrm{H}_{0}$ ) as reference for $\mathrm{H}_{1}$, and $\mathrm{H}_{1}$ as reference for the other models.

\section{Results}

The results of the correlation analysis are summarized in Table 3. For the group of genotypes included in the class "All" there was evidence of a positive correlation with the population incidence of Type I diabetes $(p<0.001)$. However, when analysing subgroups of genotypes this evidence was established by two distinct genotypes, the "Max" genotype (DQA1*0501-DQB1*0201/DQA1*0301-DQB1 *0302) from the "Strong" subgroup of "All", and the "DQ4/DQ8" genotype (DQA1*0401-DQB1*0402/ DQA1*0301-DQB1*0302) from the "Weak" subgroup of "All". The remaining subgroups of genotypes in "All" did not reach statistical significance in the correlation. Neither of the separate groups "ASP-" (DQB1-non Asp57 homozygozity) and "DQ6/X" (DQA1*0102-DQB1*0602 positive genotypes) showed a statistically significant correlation with the population Type I diabetes incidences. It is noteworthy that the protective genotype " $D Q 6 / X$ " showed close to a significant positive correlation $(p=0.066)$. Plots of the correlation data are shown in Figure 1. The group "Rest", representing the complement of "All", mirrors the correlation pattern of "All".

In agreement with the initial correlation analysis, a linear model could only be fitted for the two genotypes "Max" (DQA1*0501-DQB1*0201/ 

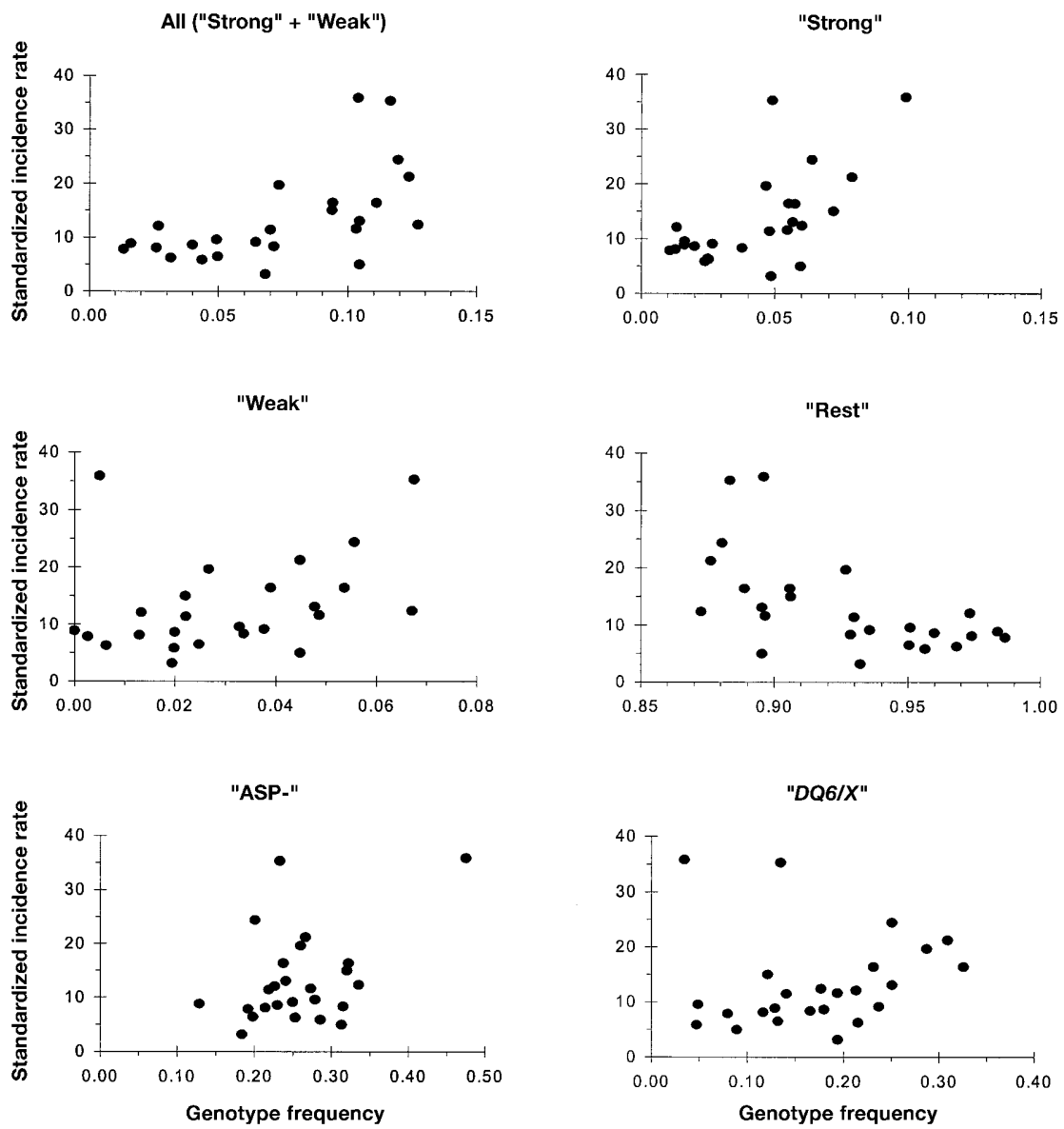

Fig. 1. Corresponding values of standardized incidence levels of Type I diabetes and population frequencies of HLA-DQ genotypes. Incidence rates are expressed per 100000 personyears

DQA1*0301-DQB1*0302) and "DQ4/DQ8" (DQA1*0401-DQB1*0402/DQA1*0301-DQB1*

$0302)$. For both of these, the linear model could be further reduced to proportionality with regression coefficients (and SEM) for "Max" and " $D Q 4 / D Q 8$ " at 700 (47) and 3500 (530), respectively and corresponding $p$ values of 0.89 and 0.57 , respectively. The fitted models are shown in Figure 2. The probability based fit takes account of both the uncertainty in ordinate (diabetes incidence), as in ordinary regression, and the uncertainty in the abscissa (genotype frequency). This explains why the fit through the origin is marginally poorer than a fit with a freely varying intercept.

Both Finland and Sardinia represent outliners, with extremely high incidence rates and special characteristics of their population's genetic history and composition. However, excluding Finland and Sardinia from the analysis hardly changed the results (data not shown).

\section{Discussion}

An ecological analysis like ours could give rise to bias and limitations in interpretation [26]. Such biases are less relevant in the present context because we are dealing with genetic factors that are supposed to remain stable throughout life. It is, however, important to emphasise that our analysis describes variation between populations as a whole and cannot be immediately applied to determine individual susceptibility. A new statistical approach has been used to correct formally for variability in the sizes of the samples that provide incidence information as well as genetic marker information. This approach can be used to refine ecological analyses in general.

Our study has shown that the geographical variability of the population risk of Type I diabetes in Europe is partly attributable to the geographical variability in the population frequency of two distinct $H L A-D Q$ susceptibility genotypes, namely DQ2/DQ8 (DQA1*0501-DQB1*0201/DQA1*0301DQB1*0302) and DQ4/DQ8 (DQA1*0401DQB1*0402/DQA1*0301-DQB1*0302). In line with this finding, the frequencies of these genotypes are highest among Type I diabetic patients in the northern part of Europe and lowest in southern Europe $[19,27]$. 
A

DQ2/DQ8

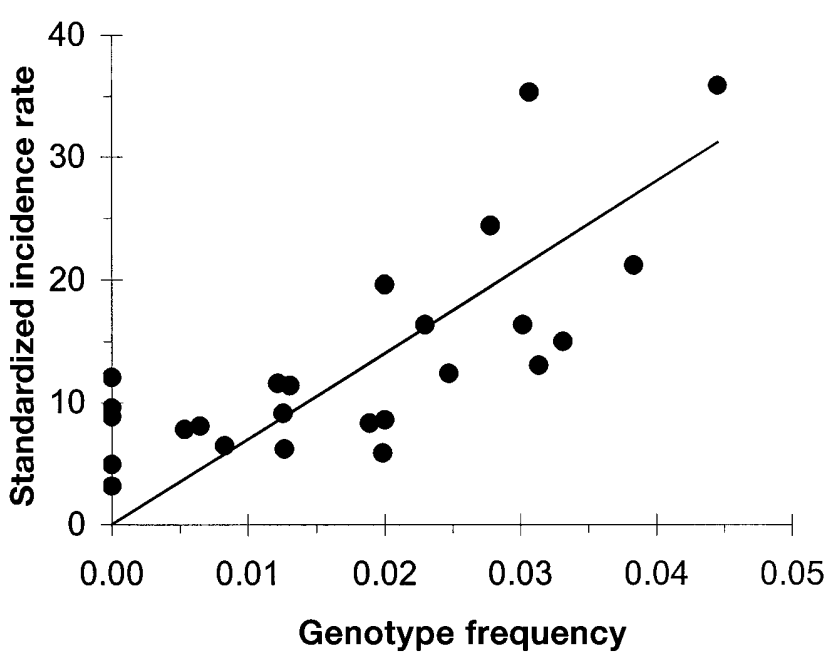

Standardized incidence rate $=700 \cdot$ HLA-frequency

B

DQ4/DQ8

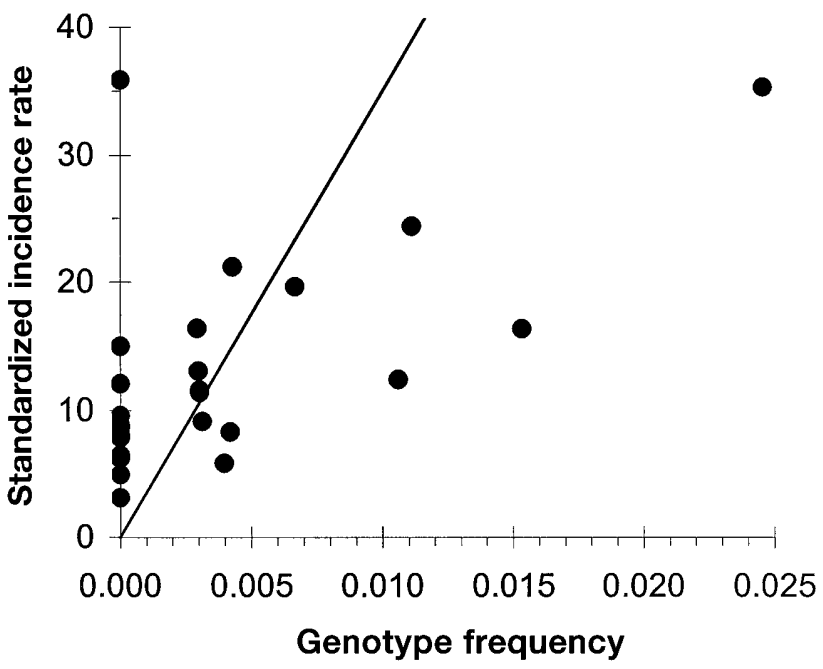

Standardized incidence rate $=\mathbf{3 5 0 0} \cdot$ HLA-frequency

Fig. 2 A, B. Corresponding values of standardized incidence levels of Type I diabetes and population frequencies of the HLA genotypes $D Q 2 / D Q 8(\mathbf{A})$ and $D Q 4 / D Q 8$ (B), respectively. Lines indicate fit to proportionality model (Table 3 ). Incidence rates are expressed per 100000 person-years

The HLA associations for Type I diabetes show heterogeneity within the European Caucasian population. While different genotypic combinations with the DR4-DQA1*0301-DQB1*0302 haplotype are most important in northern Europe, different combinations with the DR3-DQA1*0501-DQB1*0201 haplotype are more important in southern Europe [19, 27]. The same is the case for the homozygous combi- nations of these two haplotypes because DR3DQA1*0501-DQB1*0201 homozygosity plays the same role in southern Europe as DR4-DQA1*0301DQB $1 * 0302$ does in northern Europe $[19,27]$. Based on more recent knowledge of the different contribution of $H L A-D Q$ genotypes within Europe, the correlation between incidence and genomic markers can only be determined when we know which genotypes confer Type I diabetes risk in a given population. Such data are also of enormous importance for Type I diabetes prediction and intervention studies.

We are well aware of the difficulties involved in defining a population on the principle of the nation state and therefore undertooked a separate analysis of Northern Ireland and Sardinia. The vast majority of the countries in our analysis are, however, homogenous. The changes in the political map of Europe over the past decade have brought a closer identification between state and nation. The Baltic states have separated from Russia, the Czechs from Slovaks. There are two states in our analysis to which this rule might not apply: these are two successor states of the former Yugoslavia, Croatia and the Republic of Macedonia.

In contrast to previous studies which attributed much of the geographic differences in Type I diabetes incidence to variations in the prevalence of the $D Q B 1$ non-Asp57 alleles in a population, we did not find that the prevalence of $D Q B 1$ Asp57 negative genotypes (referred to as "ASP-") was correlated with Type I diabetes incidence $(p=0.20)[28,29]$. Our results confirm previous findings [30] presenting a more complex view of the genetics of Type I diabetes in a population. Our study has also not been able to demonstrate any protective effect of the HLADQB1*0602 allele at the population level. Conversely, its prevalence in the population was a close to significant positive correlation to Type I diabetes incidence $(p=0.066)$.

The presence of a strong positive correlation between population frequency of genetic susceptibility markers and population disease risk does not in itself exclude the importance of non-genetic factors (or genetic factors not accounted for in the analysis). All populations currently considered to be at a high and even extremely high Type I diabetes risk (eg. in Finland and the in other Nordic countries; Sardinia; UK), have had dramatic increases in the Type I diabetes incidence over the past decades, compared to a slower increase or no increase earlier [1,31-33]. The increases cannot be explained by secular changes in the pool of susceptibility genes and imply that no correlation would have been detected between population frequency of susceptibility genotypes and the population risk of Type I diabetes if our analysis had been performed a few decades ago. These findings suggest that non-genetic causes interact with the genetic susceptibility factors in Type I diabetes and 
that such an interaction has been enhanced over the past decades in subjects carrying specific high-risk genotypes. If so, the distribution of HLA-genotypes in newly diagnosed Type I patients should change over time in populations who have changing incidences of Type I diabetes. The hypothesis could be supported by the rapid increase of Type I diabetes incidence in children in the age group 0-4 years, observed in particular in high-incidence populations of Finland and the UK [34-36]. This is because the prevalence of the risk genotypes is generally highest in the diabetic children with early disease onset [27]. Interaction between specific high-risk genotypes and early exposure to environmental risk factors (e.g. enteroviral infections) is believed to trigger beta-cell autoimmunity in susceptible individuals, because children converting to islet cell antibodies (ICA) positivity following enterovirus infection have been shown to carry high-risk $H L A-D Q B 1$ genotypes more often than children who remained ICA negative [37].

Our study indicates avenues for further research to explain the complex causes of Type I diabetes. The currently defined high-risk populations are excellent for studies of gene-environment interactions in causing of Type I diabetes. However, comparative studies in low-risk populations could serve as an important reference. This type of research must necessarily incorporate genotyping of patients with Type I diabetes from the same populations.

Acknowledgements. Norwegian Research Council, Medinnova, Norwegian Diabetes Association. The EURODIAB studies on the epidemiology of childhood-onset Type I diabetes in Europe have been supported by the European Commission, grants BMH1-CT92-0043 and BMH4-CT96-0577. Computing assistance has been provided by M. Tvede, C. Ekstrøm, S. Esbjerg and K. Begtrup of the University of Copenhagen.

\section{Genomic data participants (centres and investigators)}

Austria: G.F. Fischer (study leader), Institut fur Blutgruppenserologie, University of Vienna. Belgium: F. C. Schuit (study leader), H. Heimberg, Department of Biochemistry, Vrije Universiteit Brussel, Brussels. Bulgaria: D. Gavrilov (study leader), Laboratory of Molecular Pathology, University Hospital of Obstetrics, Sofia. Czech Republic: P. Stastny (study leader), M. Cerna, Department of Internal Medicine, University of Texas, Dallas, Texas, U.S. A. Denmark: F. Pociot (study leader), Steno Diabetes Center, Gentofte, Denmark; H.O. Madsen (study leader), A. Svejgaard, Department of Clinical Immunology, University of Copenhagen, Copenhagen. England: A. Cox (study leader), A.M. Gonzales, Department of Medicine and Pharmacology, Section of Molecular Medicine, Royal Hallamshire Hospital, Sheffield; J. A. Todd (study leader), The Wellcome Trust Centre for Human Genetics, Kenneth Welsh, C.M. Arlett, the Transplantation Centre, Churchill Hospital, Oxford; J. Underhill (study leader), Institute of Liver Studies, King's Collage Hospital and School of Medicine and Dentistry, London, A. Kelly (study leader), D. Jenkins, C. Mijovic, K. Jacobs, A.H. Barnett, Department of Medicine, Birmingham Heartlands Hospital, Birmingham. Finland: I.Ikäheimo (study leader), A. Tiilikainen, S. Silvennoinen-Kassinen, B. Grekula, E. Saarenpåå, University of Oulu, Department of Medical Microbiology, Oulu; Dr. H. Reijonen (study leader), Medicity, University of Turku, Turku. France: S. Caillat-Zucman (study leader), Laboratory of Immnology, Necker Hospital Clinic, Paris. Germany: B. O. Boehm (study leader), Section of Endocrinology, Deptartment of Internal Medicine, University of Ulm, Ulm. Cornelius Loeliger, University of Hamburg, Hamburg. Greece: K. S. Rønningen (study leader), Deptartment of Population Health Sciences, National Institute of Public Health and Institute of Immunology, The National Hospital, Oslo, Norway; D. Undlien, Institute of Immunology, The National Hospital, Oslo, Norway. C. Papasteriades, C. Tailassi, Department of Immunology - Histocompatibility; N. Thalassinos, Department of Endocrinology and Metabolism, Evangelismos Hospital, Athens, Greece. Hungary: G: Soltesz (study leader), Hermann, Division of Endocrinology and Diabetes, Department of Paediatrics, University Medical School of Pecs, Pecs. Israel: C. Brautbar (study leader), Tissue Typing Unit, Hadassah Medical Organization, Jerusalem. Italy: R. Buzzetti (study leader), Seond Institute of Clinical Medicine, University of Rome, Rome; Physicians of the IMDIAB Study Group, Rome. Luxembourg: F. Hentges (study leader), Department of Immuno-Allergology, Medical Centre Luxembourg, C. de Beaufort, Bereldange. Norway: K.S. Rønningen (study leader), Department of Population Health Sciences, National Institute of Public Health, Institute of Immunology; D. Undlien, H. Akselsen, E. Thorsby, Institute Immunology, The National Hospital, Oslo. Northern Ireland: D. Middleton (study leader), Northern Ireland Tissue Typing Laboratory, Belfast City Hospital, Belfast. Poland: R. Ploski (study leader), HLA Laboratory, Institute of Rheumatology, Warsaw, Poland and Institute of Immunology, The National Hospital, Oslo, Norway. Portugal: A. Martinho Teixeira (study leader), H. Breda Coimbra, Centro de Histocompatibilidade do Centro, Coimbra. Republic of Macedonia: M. Kocova (study leader), Paediatric Clinic Skopje, Skopje. Romania: E. Reed (study leader), Department of Pathology, College of Physicians and Surgeons of Columbia University, New York, U.S.A. Russia: D. Gavrilov (study leader), Laboratory of Molecular Pathology, University Hospital of Obstetrics, Sofia. Sardinia: C. Carcassi (study leader), L. Contu, L. Floris, HLA Lab./Cattedra di Genetica Medica, Inst. Clin. Med., University of Cagliari, Cagliari; F. Cucca (study leader), The Wellcome Trust Centre for Human Genetics, 
Headington, Oxford, UK. Spain: C. Lopez-Larrea (study leader), F. Setien Baranda, Department of Immunology, Hospital Central Asturias, Oviedo. Sweden: I. Kockum (study leader), Department of Molecular Medicine, Karolinska Hospital; C. Sanjeevi and $\AA$ A. Lernmark, Department of Endocrinology, Karolinska Institute, Stockholm; Gisela Dahlquist, Department of Pediatrics, University of Umeå, Umeå. The Netherlands: B. O. Roep (study leader), Department Immunohaematology \& Blood Bank, University Hospital, Leiden; N. de Vries (study leader), L. B. A. van de Putte, Department of Rheumatology, University Hospital Nijmegen; H. Tijssen, Tissue typing Unit, University Hospital Nijmegen, Nijmegen.

\section{EURODIAB ACE study centres and local Study Leaders}

Austria (whole nation): E. Schober.

Belgium (Antwerp region): C. Vandewalle.

Bulgaria (western part): V. Christov.

Bulgaria (eastern part): V. Tzaneva.

Croatia (Zagreb region): G. Roglic.

Czech Republic (whole nation): J. Vavrinec.

Denmark (three counties, Jutland): J. Kreutzfeldt.

Denmark (Funen county): E. Lund.

Estonia (whole nation): T. Podar.

France (four regions): P. Czernichow.

Finland (two regions): J. Tuomilehto.

Germany (Düsseldorf region): G. Giani.

Greece (Attica region): C. Bartsocas.

Greece (five northern regions): N. Papazoglou.

Hungary (18 counties): G. Soltész.

Iceland (whole nation): A. V. Thorsson.

Italy (Lombardia region): G. Chiumello.

Italy (Lazio region): P. Pozzilli.

Italy (Sardinia): M. Songini.

Italy (Eastern Sicily): F. Purrello.

Israel (whole nation): Z. Laron.

Latvia (whole nation): G. Brigis.

Lithuania (whole nation): B. Urbonaite.

Luxembourg (whole nation): C. de Beaufort.

The Netherlands (five regions): $M$. Reeser.

Norway (eight regions): G. Joner.

Poland (nine western provinces): D. Woznicka.

Poland (three cities): Z. Szybinski.

Portugal (Madeira Island): S. Abreu.

Portugal (Portalegre region): C. Menezes.

Portugal (Algarve region): E. Pina.

Romania (Bucharest region): C. Ionescu-Tirgoviste.

Slovakia (whole nation): D. Michalková.

Slovenia (whole nation): C. Krzisnik.

Spain (Catalunya region): A. Goday.

Sweden (two counties): G. Dahlquist.

United Kingdom (Northern Ireland): D. Hadden.

United Kingdom (Oxford region): P. Bingley.

United Kingdom (Leeds region): P. A. McKinney.

United Kingdom (Leicestershire region): H. Botha.

\section{EURODIAB ACE Steering Committee}

P. Bingley (London, UK); G. Dahlquist (Umeå, Sweden); E. Gale (London, UK); A. Green (Odense, Denmark); K. Ohm Kyvik (Odense, Denmark); C. Levy-Marchal (Paris, France); R. Lounamaa (Bristol, UK); G. Soltész (Pécs, Hungary); M. Songini (Cagliari, Italy). G. Brutti (Odense, Denmark) has provided expert secretarial assistance.

\section{References}

1. EURODIAB ACE Study Group (2000) Variation and trends in incidence of childhood diabetes in Europe. Lancet 355: 873-876

2. Green A, Gale EA, Patterson CC (1992) Incidence of childhood-onset insulin-dependent diabetes mellitus: the EURODIAB ACE Study. Lancet 339: 905-909

3. Karvonen M, Tuomilehto J, Libman I, LaPorte R (1993) A review of the recent epidemiological data on the worldwide incidence of Type I (insulin-dependent) diabetes mellitus. World Health Organization DIAMOND Project Group. Diabetologia 36: 883-892

4. Davies JL, Kawaguchi Y, Bennett ST et al. (1994) A genome-wide search for human Type I diabetes susceptibility genes. Nature 371: 130-136

5. Copeman JB, Cucca F, Hearne CM et al. (1995) Linkage disequilibrium mapping of a Type I diabetes susceptibility gene (IDDM 7) to chromosome 2q31-q33. Nat Genet 9: 80-85

6. Todd JA, Farrall M (1996) Panning for gold: genome-wide scanning for linkage in Type I diabetes. Hum Mol Genet 5: $1443-1448$

7. Todd JA, Bell JI, McDevitt HO (1987) HLA-DQ beta gene contributes to susceptibility and resistance to insulin-dependent diabetes mellitus. Nature 329: 599-604

8. Horn G, Bugawan T, Long C, Erlich H (1988) Allelic sequence variation of the HLA-DQ loci: Relationship to serology and to insulin-dependent diabetes mellitus susceptibility. Proc Natl Acad Sci U S A 85: 6012-6016

9. Baisch JM, Weeks T, Giles R, Hoover M, Stastny P, Capra JD (1990) Analysis of HLA-DQ genotypes and susceptibility in insulin-dependent diabetes mellitus. N Engl J Med 322: 1836-1841

10. Thorsby E, Rønningen KS (1993) Particular HLA-DQ molecules play a dominant role in determining susceptibility or resistance to Type I (insulin-dependent) diabetes mellitus. Diabetologia 36: 371-377

11. Morel PA, Dorman JS, Todd JA, McDevitt HO, Trucco M (1988) Aspartic acid at position 57 of the HLA-DQ beta chain protects against type I diabetes: a family study. Proc Natl Acad Sci U S A 85: 8111-8115

12. Rønningen KS, Iwe T, Halstensen TS, Spurkland A, Thorsby E (1989) The amino acid at position 57 of the HLA-DQ beta chain and susceptibility to develop insulin-dependent diabetes mellitus. Hum Immunol 26: 215-225

13. Todd JA, Mijovic C, Fletcher J, Jenkins D, Bradwell AR, Barnett AH (1989) Identification of susceptibility loci for insulin-dependent diabetes mellitus by trans-racial gene mapping. Nature 338: 587-589

14. Khalil I, d'Auriol L, Gobet M et al. (1990) A combination of HLA-DQ beta Asp57-negative and HLA DQ alpha Arg52 confers susceptibility to insulin-dependent diabetes mellitus. J Clin Invest 85: 1315-1319 
15. Khalil I, Deschamps I, Lepage V, al-Daccak R, Degos L, Hors J (1992) Dose effect of cis- and trans-encoded HLADQ alpha beta heterodimers in IDDM susceptibility. Diabetes 41: 378-384

16. Rønningen KS, Spurkland A, Iwe T, Vartdal F, Thorsby E (1991) Distribution of HLA-DRB1, -DQA1 and -DQB1 alleles and DQA1-DQB1 genotypes among Norwegian patients with insulin-dependent diabetes mellitus. Tissue Antigens 37: 105-111

17. Rønningen KS, Gjertsen HA, Iwe T, Spurkland A, Hansen T, Thorsby E (1991) Particular HLA-DQ alpha beta heterodimer associated with IDDM susceptibility in both DR4-DQw4 Japanese and DR4-DQw8/DRw8-DQw4 whites. Diabetes 40: 759-763

18. Pugliese A, Gianani R, Moromisato R et al. (1995) HLA$\mathrm{DQB} 1 * 0602$ is associated with dominant protection from diabetes even among islet cell antibody-positive first-degree relatives of patients with IDDM. Diabetes 44: 608-613

19. Rønningen K, Spurkland A, Tait B et al. (1993) HLA class II associations in insulin-dependent diabetes mellitus among black, Caucasoids and Japanese. In: Tsuji K, Aizawa H, Sasazuki T (eds). HLA 1991. Proceedings of the Eleventh International Histocompatibility Workshop and Conference. Oxford University Press, Oxford, pp 713-722

20. Kimura A, Dong RP, Harada H, Sasazuki T (1992) DNA typing of HLA class II genes in B-lymphoblastoid cell lines homozygous for HLA. Tissue Antigens 40: 5-12

21. Olerup O, Aldener A, Fogdell A (1993) HLA-DQB1 and -DQA1 typing by PCR amplification with sequence-specific primers in 2 hours. Tissue Antigens 41: 119-134

22. Rønningen KS (1997) Genetics in the prediction of insulindependent diabetes mellitus: from theory to practice. Ann Med 29: 387-392

23. Kendall M, Gibbons J (1990) Rank correlation methods, 5 edn. Oxford University Press, Oxford

24. Anderson TW (1976) Estimation of linear functional relationships. Journal of the Royal Statistical Society Series B, Springer, New York, 38: 1-36

25. Johansen S (1984) Functional relations, random coefficients, and nonlinear regression with application to kinetic data. Springer Lecture Notes on Statistics, Vol. 22

26. Rothman K, Greenland S (1998) Modern Epidemiology. Lippincott-Raven Publishers, Philadelphia, pp 469-471
27. Caillat-Zuckman S, Djilali-Saiah I, Timsit J et al. (1997) Insulin dependent diabetes mellitus (IDDM): 12th International Histocompatibility Workshop study. In: Charron D (ed) HLA: Genetic diversity of HLA. Functional and medical applications. EDK, Paris, pp 389-398

28. Dorman JS, LaPorte RE, Stone RA, Trucco M (1990) Worldwide differences in the incidence of type I diabetes are associated with amino acid variation at position 57 of the HLA-DQ beta chain. Proc Natl Acad Sci U S A 87: 7370-7374

29. Forbes LV, Brown LJ, Scott RS (1993) HLA-DQ beta typing and non-Asp57 alleles in IDDM and nondiabetic subjects in New Zealand. Diabetes Care 16: 1179-1183

30. Reijonen H, Ilonen J, Knip M, Akerblom HK (1991) HLADQB1 alleles and absence of Asp 57 as susceptibility factors of IDDM in Finland. Diabetes 40: 1640-1644

31. Ustvedt HJ, Olsen E (1977) Incidence of diabetes mellitus in Oslo, Norway 1956-65. Br J Prev Soc Med 31: 251-257

32. Joner G, Søvik O (1981) Incidence, age at onset and seasonal variation of diabetes mellitus in Norwegian children, 1973-1977. Acta Paediatr Scand 70: 329-335

33. Krolewski AS, Warram JH, Rand LI, Kahn CR (1987) Epidemiologic approach to the etiology of type I diabetes mellitus and its complications. N Engl J Med 317: 1390-1398

34. Tuomilehto J, Virtala E, Karvonen M et al. (1995) Increase in incidence of insulin-dependent diabetes mellitus among children in Finland. Int J Epidemiol 24: 984-992

35. Tuomilehto J, Karvonen M, Pitkaniemi J et al. (1999) Record-high incidence of Type I (insulin-dependent) diabetes mellitus in Finnish children. The Finnish Childhood Type I Diabetes Registry Group. Diabetologia 42: 655-660

36. Gardner SG, Bingley PJ, Sawtell PA, Weeks S, Gale EA (1997) Rising incidence of insulin dependent diabetes in children aged under 5 years in the Oxford region: time trend analysis. The Bart's-Oxford Study Group. BMJ 315: 713-717

37. Hiltunen M, Hyoty H, Knip M et al. (1997) Islet cell antibody seroconversion in children is temporally associated with enterovirus infections. Childhood Diabetes in Finland (DiMe) Study Group. J Infect Dis 175: 554-560 